\title{
58. Les eléments culturels dans la méthode de Français Saison $1^{1}$
}

\section{Lale ONGUNYURT ${ }^{2}$}

\section{Rıfat GÜNDAY3}

APA: Ongunyurt, L.; Günday, R. (2021). Les eléments culturels dans la méthode de Français Saison 1. RumeliDE Dil ve Edebiyat Araştırmalar Dergisi, (24), 1029-1048. DOI: 10.2900o/rumelide.995475.

\section{Résumé}

Connaitre une langue, c'est de pouvoir l'utiliser dans la vie réelle. Ce qui est important, ce n'est pas de renforcer la connaissance en termes de grammaire, mais plutôt de pouvoir construire la communication et de réaliser l'interaction avec les autres en langue cible. Dans cette perspective, les manuels couvrent, non seulement des documents produits pour des objectifs didactiques, mais aussi les matériels authentiques qui ont des caractéristiques culturelles. Cette étude vise à rechercher, dans la méthode de Français Saison 1, les documents culturels en termes d'images, de textes et de vocabulaires; à les classifier sous la perspective de la culture française, de la culture francophone et du multiculturalisme; à analyser leurs situations d'utilisation dans les activités pour développer les compétences langagières. Ce manuel réserve une place importante à la dimension socio-culturelle. Les thèmes abordés sont plutôt relatifs à la vie quotidienne. Cependant, il existe certains documents culturels comme les textes littéraires, les arts et les monuments. Pour la dimension culturelle, la plus importante différence de ce manuel, c'est que dans le cadre de sociolinguistique il donne place à une expression idiomatique de la culture française ou de la culture francophone dans chaque partie « actu culture ». Ainsi les apprenants apprennent l'utilisation de certaines expressions idiomatiques dans un contexte socio-culturel. Il se trouve des exemples de la culture française, de la culture francophone et du multiculturalisme. Mais, il existe peu d'exemples sur le multiculturalisme. On présente les éléments culturels d'une part pour citer des savoirs, et d'autre part pour développer toutes les compétences langagières de base, les composantes linguistiques, et de plus pour les compétences communicatives et interculturelles.

Mots-Clés: Les éléments culturels, le manuel, la langue étrangère, l'enseignement, l'apprentissage

\section{Saison 1 yöntem kitabında kültürel öğeler}

\section{$\ddot{O} \mathbf{z}$}

Bir dili bilmek, onu gerçek yaşamda kullanabilmektir. Önemli olan dilbilgisi konusunda güçlü bilgiye sahip olmak değil, hedef dilde başkaları ile iletişim kurabilmek ve birlikte eylemler gerçekleştirebilmektir. Bu çalışmanın amacı, Saison 1 adlı Fransızca yöntem kitabında görsel (imaj), metin ve sözcük düzeyinde yer alan kültürel öğeleri araştırmak, bunları Fransız kültürü, frankofon kültür ve çok kültürlülük bağlamında sınıflandırmak ve dil becerilerinin geliştirilmesine yönelik etkinliklerde kullanımlarını irdelemektir. Bu yöntem kitabı özellikle sosyo kültürel boyuta büyük

Cet article est issu du mémoire intitulé Dimension culturelle dans les livres de méthode de Français aux écoles Galatasaray. YL, Ondokuz Mayıs Üniversitesi, Eğitim Fakültesi, Yabancı Diller Eğitimi Bölümü, Fransız Dili Eğitimi Bölümü ABD (Samsun, Turkey), laleongunyurt@gmail.com, ORCID ID: oooo-0oo3-1682-2183. [Araştırma makalesi, Makale kayıt tarihi: 17.05.2021-kabul tarihi: 20.09.2021; DOI: 10.29000/rumelide.995475]

Prof Dr., Ondokuz Mayıs Üniversitesi, Eğitim Fakültesi, Yabancı Diller Eğitimi Bölümü, Fransız Dili Eğitimi Bölümü ABD (Samsun, Turkey), rgunday@omu.edu.tr, ORCID ID: oooo-0001-8356-5098.

Adres | Address

RumeliDE Dil ve Edebiyat Araşturmaları Dergisi Osmanağa Mahallesi, Mürver Çiçeği Sokak, No:14/8 Kadıköy - ISTANBUL / TÜRKIYE 34714 e-posta: editor@rumelide.com

RumeliDE Journal of Language and Literature Studies Osmanağa Mahallesi, Mürver Çiçeği Sokak, No:14/8

Kadıköy - ISTANBUL / TURKEY 34714 tel: +90 $5057958124,+902167730616$

mail: editor@rumelide.com

phone: +90 505 7958124, +90 2167730616 
önem vermektedir. Bununla birlikte, ele alınan konular daha çok güncel yaşamla ilgilidir. Edebi metinler, sanat ve tarihi eserler de kültürel öğeler olarak yer almaktadır. Söz konusu yöntem kitabının en özgün yanı kültürel bağlamda her ünitenin kültür köşesinde Fransız kültürü ve frankofon kültüre ait bir deyimin sunulmasıdır. Böylece öğrenenler, bazı deyimleri sosyo kültürel bağlama dayalı olarak öğrenme olanağı bulmaktadırlar. Kitapta Fransız kültürü, frankofon kültür ve çok kültürlülük bağlamında öğeler yer almaktadır. Ancak diğer kültürlere ait çok az örneğe rastlanmaktadır. Kültürel öğelere, bir yandan bilgi aktarımı amacına yönelik olarak yer verilirken, diğer yandan da temel dil becerilerinin, dil bileşenlerinin ve ayrıca iletişim ve kültürlerarası becerilerin geliştirilmesi amacına yönelik yer aldıkları görülmektedir.

Anahtar kelimeler: Kültürel öğeler, yöntem kitabı, yabancı dil, öğretim, öğrenim

\title{
Cultural elements in the method book Saison 1
}

\begin{abstract}
Knowing a language is being able to use it in real life. The important thing is not to have an advanced knowledge of grammar, but to be able to communicate with others and to act together in the target language. In line with this perspective, method books do not find it sufficient to include only educational materials, but also include original materials with cultural dimensions. The aim of this study is to investigate cultural elements in the visual (image), textual and word levels in the French method book named Saison 1, to classify them in the context of French culture, Francophone culture and multiculturalism, and to examine their use in activities aimed at improving French language skills. The present method book gives great emphasis on the socio-cultural dimension. The issues dealt with in a socio-cultural context are more relevant to current life. In addition, literary texts, art and historical works are also included as cultural elements. The most unique aspect of the method book regarding cultural aspect is the presentation of an idiom of French culture and Francophone culture in the cultural corner of each unit. Thus, learners have the opportunity to learn some idioms based on the socio-cultural context. The book contains elements regarding French culture, Francophone culture and multiculturalism. However, there are very few examples related to the other cultures. On the one hand, cultural elements are given for the purpose of knowledge transfer, it is seen that they are also given places for the purpose of developing basic language skills, language components, as well as communication and intercultural skills.
\end{abstract}

Keywords: Cultural components, method book, foreign language, teaching, learning

\section{Introduction}

Il est toujours possible de voir les changements en didactique des langues étrangères. Au passé, les conceptions de l'enseignement/apprentissage des langues étrangères se reposaient principalement sur la maîtrise de la connaissance grammaticale (Richards, 2006). Mais cette approche qui a continué longtemps, a laissé sa place au développement des compétences langagières de base. Parce que connaître la langue, c'est de pouvoir l'utiliser dans la vie quotidienne. Ce qui est important, ce n'est pas de renforcer la connaissance en termes de grammaire, mais plutôt de développer la compétence communicative sous différents aspects. C'est-à-dire pouvoir construire la communication et réaliser l'interaction avec les autres en langue cible dans tous les domaines. De nos jours, le besoin aux langues étrangères ne se sent pas seulement pour les œuvres écrites, mais également pour toutes les activités de la vie sociale.

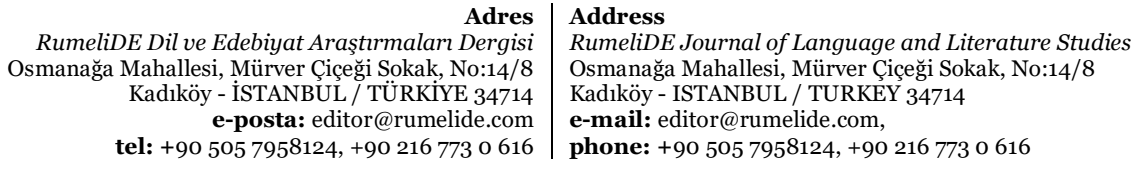


Du fait que le but est de pouvoir utiliser la langue cible dans tous les domaines et tous les contextes socio-culturels, la dimension culturelle gagne l'importance dans l'enseignement/apprentissage de la langue étrangère. "L’enseignement des langues a longtemps occulté la dimension culturelle qui est véhiculée dans tout rapport à la langue au nom d'une dimension fonctionnelle, cependant, les nouvelles orientations didactiques ont voulu prendre en considération le rapport unissant langue et culture, en rebaptisant l'enseignement des langues-cultures.” (Boubakour, 2010).

Alors que la fonction de la langue est la communication, sa formation s'appuie sur la culture. On considère la langue comme un produit culturel. Il est difficile de parler d'une langue sans prendre en considération sa culture, et aussi d'une communication efficace sans l'utiliser convenablement au contexte socio-culturel (Günday et Aycan, 2018, 534). Pour ne pas bloquer la communication, il est inévitable de faire attention aux différences socio-culturelles à l'usage de la langue cible (Baylon et Mignot, 2005, 9).

$\mathrm{Au}$ XIXe siècle, d'abord le contenu culturel était axé sur les hauts faits culturels comme la littérature et les arts dans l'enseignement des langues étrangères. L'objectif était plutôt de transmettre des savoirs encyclopédiques à l'égard de la civilisation de la langue cible. Plus tard, vers la fin du XIXe siècle, des faits politiques, économiques, techniques, géographiques et historiques de la culture cible étaient parus dans l'apprentissage (Byram, Zarate et Neuner 1997, 59-61, cité par Nijenkamp, 2017, 5). A la deuxième moitié du XXe siècle les éléments culturels de la vie quotidienne commencent de plus en plus à devenir importants dans l'enseignement des langues étrangères. Grâce au développement des technologies audiovisuelles, les documents authentiques et culturels commencent à jouer un rôle primordial (Risager 2007, 73). Dans les méthodes traditionnelles, on donnait l'importance à la dimension culturelle pour que les apprenants développent leur niveau intellectuel, or de nos jours le but des méthodes contemporaines est d'assurer l'utilisation efficace de la langue cible (Bertocchini et Costanzo, 2008, 78).

Les approches contemporaines accentuent l'importance de connaitre la culture de la langue cible. Puren $(2004,10)$ indique le rapport de langue-culture comme l'un des points communs entre l'approche communicative et l'approche actionnelle. Surtout l'approche actionnelle qui est formée selon les principes de CECRL, aborde le rapport de langue-culture dans le cadre de co-culture et co-langue. Selon Puren (2002, 62), parallèlement à cette approche il faut demander aux apprenants des tâches basées sur les co-actions sociales. Le but de l'enseignement/apprentissage de la langue étrangère doit élever les apprenants en tant que les individus qui peuvent connaître les cultures différentes et réaliser aisément les interactions en langue cible (Cuq, 2009; Rosen, 2009, 7).

Dans les années quatre-vingt et quatre-vingt-dix, avec l'approche communicative, le multiculturalisme et l'interculturalité commencent également à prendre leur place. Ainsi, une dimension interculturelle remplace la dimension culturelle. A ce développent, l'augmentation des possibilités de communication entre les gens et les sociétés joue un rôle déterminant. Et selon l'approche interculturelle, l'objectif n'est plus seulement d'un enseignement explicite des faits culturels, mais plutôt est de créer une tendance à privilégier les processus de perception et la réflexion sur les relations entre différentes cultures et de les pratiquer dans la communication et l'interaction avec les autres. Il n'est pas suffisant de savoir des faits culturels, mais de réfléchir sur sa propre culture afin de pouvoir comprendre les aspects de la culture cible (Byram, Zarate, Neuner 1997, 63-72). Le cadre commun de référence pour les langues accentue l'importance de la prise de conscience interculturelle dans l'enseignement/apprentissage de langue étrangère :

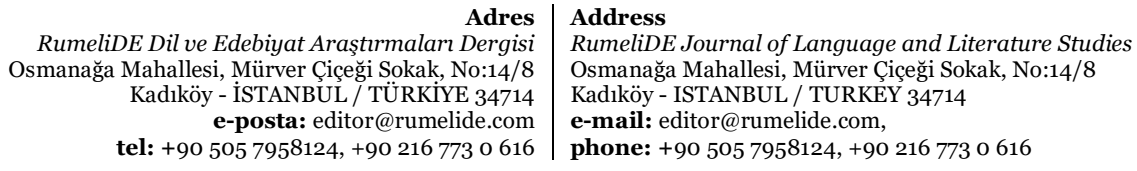


La connaissance, la conscience et la compréhension des relations, (ressemblances et différences distinctives) entre «le monde d'où l'on vient » et « le monde de la communauté cible » sont à l'origine d'une prise de conscience interculturelle. Il faut souligner que la prise de conscience interculturelle inclut la conscience de la diversité régionale et sociale des deux mondes. Elle s'enrichit également de la conscience qu'il existe un plus grand éventail de cultures que celles véhiculées par les L1 et L2 de l'apprenant. Cela aide à les situer toutes deux en contexte. Outre la connaissance objective, la conscience interculturelle englobe la conscience de la manière dont chaque communauté apparaît dans l'optique de l'autre, souvent sous la forme de stéréotypes nationaux (CECRL, 2001, 83).

Dans cette perspective, les manuels doivent contenir, non seulement des documents produits pour des objectifs didactiques, mais aussi les matériels authentiques qui ont des caractéristiques culturelles. Et, en plus, présenter les éléments culturels du pays où est parlée la langue cible n'est pas suffisant, il faut connaître les autres cultures aussi. Les apprenants peuvent avoir des connaissances sur des éléments culturels, et ils peuvent comparer la culture d'emploi de leur langue maternelle à celle de la langue cible. A l'heure actuelle, les manuels distinguent une large place à la culture de la langue cible, et les documents interculturels y sont également présents même si leurs nombres sont plus moins.

Les éléments culturels peuvent prendre place des façons différentes dans les manuels. Les manuels peuvent réserver une partie à la culture dans chaque unité, dans les autres parties aussi les documents culturels peuvent être présents et il est possible de continuer les activités ou exercices en profitant des éléments culturels.

Pendant l'enseignement/apprentissage de langue étrangère, l'instruction planifiée est un grand réconfort d'abord pour l'enseignant, puis pour l'apprenant. La méthode assure une facilité à l'enseignant puisqu'on saura comment exploiter le cours en la suivant. Le manuel scolaire est le guide le plus important dans les étapes à définir pour atteindre les objectifs du cours ; déterminer les contenus, les thèmes, les activités. Et il contient plusieurs documents différents. Donc, il faut considérer encore le manuel comme le matériel de base dans l'enseignement/apprentissage de la langue étrangère. Dans cette méthode de français, toutes les parties, les activités et les documents sont bien organisés afin de développer les compétences langagières, communicatives et interculturelles. Ainsi, suivre les manuels bien formés augmentera la réussite et rendra facile le processus d'arriver à l'objectif.

Cette étude vise à rechercher les éléments culturels dans la méthode de français Saison 1 qui est formée selon l'approche actionnelle. Au cours de cette étude, d'abord nous avons déterminé des éléments culturels en termes d'images, de textes et de vocabulaires, et puis nous avons classifié des documents en trois catégories selon la culture à laquelle ils appartiennent : la culture française, des pays francophones et d'autres pays dans le contexte de multiculturalisme. Enfin, nous avons analysé l'exploitation de ces éléments culturels pour développer les compétences langagières.

\section{Les problèmes}

Dans cette étude nous avons recherché des réponses aux questions suivantes :

1) Quels sont les thèmes abordés dans le contexte socioculturel?

2) Quelle est la part d'images, de textes et vocabulaires culturels ?

3) A propos de quelle culture les documents se trouvent les plus ?

4) Quels sont les objectifs des exercices, des activités et des tâches pratiquées dans le manuel ?

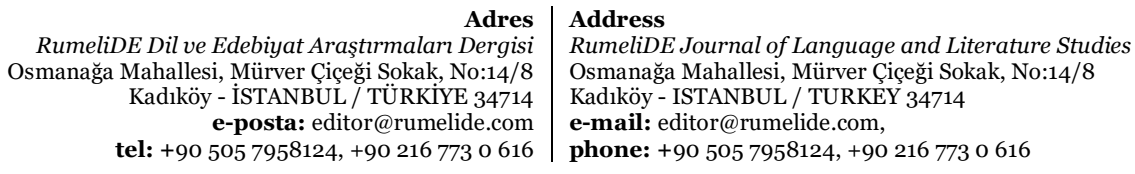




\section{L'objectif de l'Etude}

Cette étude vise à rechercher, dans la méthode de Français Saison 1, les documents culturels en termes d'images, de textes et vocabulaires ; à les classifier sous la perspective de la culture française, la culture francophone et le multiculturalisme et à analyser leurs situations d'utilisation dans les activités pour développer les compétences langagières.

\section{L'importance de la Recherche}

De nos jours, l'apprentissage des langues étrangères est obligatoire afin de vivre dans un monde global. Pour satisfaire ce besoin, les outils et les documents à utiliser ou exploiter sont aussi importants que les techniques, les méthodes et les stratégies à suivre. Depuis longtemps, dans les classes les manuels sont devenus des matériels importants du processus d'apprentissage, mais également des méthodes d'enseignement (Riquois, 2010). Malgré tous les développements aux technologies de l'information et de la communication, ces manuels continuent à conserver leurs places primordiales en didactique des langues étrangères. Cependant les continus des manuels ont changé de plus en plus, et surtout les documents authentiques et culturels ont commencé à prendre une large place. Dans ce point, les documents authentiques qui sont également des produits culturels sont des ressources très importantes. Ainsi, pour l'enseignement/apprentissage efficace d'une langue étrangère, l'enseignement des règles de grammaire n'est pas une voie convenable, il faut apprendre la langue cible dans son contexte d'emploi socio-culturel. Dans cette perspective, les éléments culturels peuvent aider bien l'utilisation de la langue en présentant plusieurs connaissances sur le pays où est parlée cette langue ou sur les autres pays. Par conséquent, par le moyen de ces documents culturels, les apprenants trouvent l'occasion de se mettre au contact avec la culture de la langue apprise. C'est pour cette raison qu'il est important d'étudier les manuels scolaires et d'évaluer l'exploitation des éléments culturels.

\section{Cadre Théorique}

\section{La Culture}

Selon Larousse (2018) la culture est "ensemble des phénomènes matériels et idéologiques qui caractérisent un groupe ethnique ou une nation, une civilisation, par opposition à un autre groupe ou à une autre nation". Quant à l'UNESCO, cette organisation internationale fait une large définition de culture : «Dans son sens le plus large, la culture peut aujourd'hui être considérée comme l'ensemble des traits distinctifs, spirituels, matériels, intellectuels et affectifs, qui caractérisent une société ou un groupe social. Elle englobe, outre les arts, les lettres et les sciences, les modes de vie, les lois, les systèmes de valeurs, les traditions et les croyances » (1982).

Le terme de " culture » recouvre les valeurs, les croyances, les langues, les arts, les cuisines, les traditions, les institutions et les modes de vie par lesquels une personne ou une communauté exprime les significations de leur son existence et leur développement. Par contre, l'expression "identité culturelle » est comprise comme l'ensemble des références culturelles par laquelle une personne ou une communauté se définit, se manifeste et souhaite être reconnu : l'identité culturelle implique les libertés inhérentes à la dignité de la personne et intègre dans un processus permanent de la diversité culturelle (Sow, 2009).

La culture est comme un tapis, une couverture qui concerne toutes les couleurs de la société. Une image, un geste, un vocabulaire, une structure de phrase et même une prononciation peuvent être considérés

\footnotetext{
Adres | Address

RumeliDE Dil ve Edebiyat Araştırmaları Dergisi $\quad$ RumeliDE Journal of Language and Literature Studies

Osmanağa Mahallesi, Mürver Çiçeği Sokkak, No:14/8 $\quad$ Osmanağa Mahallesi, Mürver Çiçeği Sokak, No:14/8

Kadıköy - ÍSTANBUL / TÜRKIYE 34714 Kadıköy - ISTANBUL / TURKEY 34714

e-posta: editor@rumelide.com e-mail: editor@rumelide.com,

tel: +90 505 7958124, +90 2167730616 phone: +90 505 7958124, +90 2167730616
} 
comme les produits culturels. Et bien sûr, on peut dire que par le moyen de la langue il est facile de la transmettre aux communautés diverses. De plus, la culture qui est un élément primordial à l'acquisition de la langue maternelle, a également une dimension importante dans l'enseignement/apprentissage d'une langue étrangère.

Des manières de table aux relations entre les sexes, du langage corporel aux cultures régionales, de la littérature à la musique les apprenants peuvent avoir beaucoup de savoirs sur la culture de la langue cible et les intégrer à leur vie quotidienne. "Le savoir socioculturel englobe les aspects de la vie quotidienne, les conditions de vie, les relations interpersonnelles, les valeurs et croyances, la communication non verbale et les conventions relatives à l'hospitalité et aux comportements rituels. Ces éléments recouvrent les informations relatives aux aspects de la culture » (Nijenkamp, 2017, 11). C'est pour cette raison que, de nos jours, soient les approches et les méthodes, soient les manuels réservent une large place à l'intégration du savoir culturel.

\section{L'interculturalité}

A l'heure actuelle, les voyages sont augmentés entre les pays et toutes les frontières sont disparues dans le monde virtuel. Les gens sont toujours en communication et en interaction avec les autres ; soit avec ceux de sa société, soit ceux des pays différents dans le monde global d'aujourd'hui. Dans le cadre des langues étrangères, il faut discuter les termes d'interculturalité car la réalisation de la communication et de l'interaction dépend de la connaissance de la culture de l'autre. Communiquer entre des personnes de cultures différentes exige en général une médiation interculturelle:

Les aptitudes et les savoir-faire interculturels comprennent

- la capacité d'établir une relation entre la culture d'origine et la culture étrangère

- la sensibilisation à la notion de culture et la capacité de reconnaître et d'utiliser des stratégies variées pour établir le contact avec des gens d'une autre culture

- la capacité de jouer le rôle d'intermédiaire culturel entre sa propre culture et la culture étrangère et de gérer efficacement des situations de malentendus et de conflits culturels

- la capacité à aller au-delà de relations superficielles stéréotypées (CECRL 2001, 84).

Nombreux auteurs revendiquent l'importance de l'enseignement/l'apprentissage de la culture dans les cours de langue étrangère. Selon Byram, « l'étude d'une langue étrangère (...) permet d'appréhender une autre culture, et à cet égard inclut des facteurs humains et sociaux. Tout au long de son cursus, on peut inciter l'élève à examiner ce qu'il connait d'un autre point de vue, notamment en ce qui concerne le comportement humain ; ainsi ses horizons seront élargis et les sentiments d'insularité pourront se dissiper. » (1992).

À la suite des travaux de nombreux chercheurs ou auteurs, on constate qu'ils distinguent les objectifs pratiques, éducatifs, politiques et culturels de l'enseignement/apprentissage des langues étrangères en contexte scolaire. Les pensées incluent des objectifs culturels que ceux-ci doivent permettre aux élèves de connaître mieux la littérature, la civilisation, les arts, les modes de vie, etc. d'un autre pays ou d'un autre peuple.

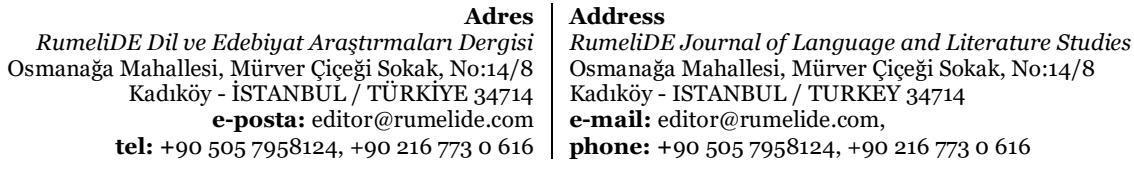


Selon les chercheurs, on peut séparer ces objectifs en quatre groupes. Le premier, c'est celui de la communication, le deuxième est celui de la prise de conscience de la langue, le troisième est celui de la prise de conscience de la dimension culturelle et le dernier est un regroupement des précédents. Dans la prise de conscience de la dimension culturelle, l'objectif doit se traduire par une proposition d'un aperçu de la civilisation et de la culture des pays francophones, un encouragement des attitudes positives envers la langue et les peuples qui la parlent et enfin la promotion de la compréhension vis à vis d'autres cultures.

Lorsque les compétences interculturelles ne sont pas développées, on peut vivre des situations de malentendu dans la communication. De plus, la communication interculturelle exige le développement des dimensions suivantes : les savoirs, le savoir-faire et le savoir-être (Lázár, Huber-Kriegler, Lussier, Matei \& Peck 2007, 27, cité par Nijenkamp, 2017, 16). Les savoirs couvrent toutes les connaissances relatives à la société. Le savoir-faire est de pouvoir faire des comparaisons entre les cultures différentes. Quant au savoir-être, c'est de pouvoir les intégrer à la communication et à la vie sociale. L'objectif de toutes ces dimensions est d'effectuer une communication efficace et une interaction avec l'autre en langue cible. « D'après l'approche interculturelle il ne faut pas considérer les élèves comme des touristes mais comme des futurs médiateurs interculturels. " (Nijenkamp, 2017, 22). Ainsi, les apprenants peuvent développer leurs capacités de comparaison, d'interprétation et de mise en relation les cultures différentes.

\section{La Langue}

La langue est un moyen de communication. S'il faut la définir un peu en détail, la langue est un système de signes vocaux, éventuellement graphiques, propre à une communauté d'individus qui l'utilisent pour s'exprimer et communiquer entre personnes.

Selon la définition de la langue dans le dictionnaire linguistique : elle est considérée comme un moyen de communication mutuelle entre personnes ; un système de voix polyvalent et sophistiqué, qui permet à chaque société d'être transférée à d'autres à l'aide de règles communes façonnées selon leurs jugements de valeur : en termes de voix, de forme et de signification (Aksan, 2007). Selon Yaguello $(2003,7)$ la langue est "un système symbolique qui est engagé aux relations sociales." Dans ce système, la première condition pour être une société, c'est d'avoir une langue commune et c'est de se comprendre. Les points communs dans les définitions de langue : la communication, la relation sociale et la dimension sociale et fonctionnelle (Günday et Aycan, 2018, 534).

La langue, une faculté importante d'être humain, est un élément puissant sous-tendant la relation qu'une société établira avec d'autres sociétés. Pour cette raison, la langue est une entité sociale et vivante dont son importance augmente du passé au présent. La langue est un outil qui reflète la façon de penser de la société à laquelle elle appartient. Puisque la langue se développe avec la société, la première condition pour maîtriser une langue étrangère est de penser comme cette société (Er, 2006).

L'un des objectifs dans l'apprentissage/enseignement des langues est d'effectuer la communication qui est la fonction essentielle de la langue (Kartal, 2001). Parce qu'on a besoin toujours une langue pour réaliser la communication.

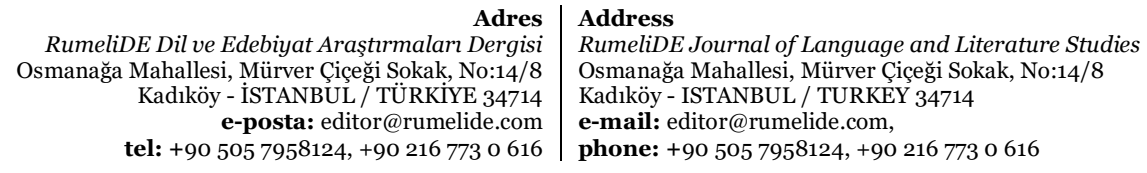




\section{Le Rapport Entre la Culture et la Langue}

Pour une société, la langue et la culture sont des composantes importantes en tant que deux éléments liés l'un à l'autre. La culture est d'une part le produit de la langue, et d'autre part elle influence la langue et forme son emploi. « La langue et la culture ressemblent à un iceberg ; la partie visible est la langue, la partie cachée dans l'eau représente la culture » (Jiang, 2000, 328). Par conséquent, on a des valeurs qui s'affectent et peuvent provoquer leur formation. Et comment les éléments culturels d'une société peuvent-ils être transférés d'une personne à l'autre ou d'un pays à l'autre? Sans doute, c'est grâce à la langue qui est à la fois un produit de la société. Dans les sociétés humaines, la langue permet de véhiculer le mieux une culture, tant orale qu'écrite.

La langue est l'une des méthodes les plus efficaces et les plus largement utilisées pour transmettre tout dans nos vies. Les peintures dessinées sur les murs de l'ancien dans la caverne montrent que les gens ont besoin de s'expliquer et de se comprendre dans toutes les époques et dans tous les lieux. Parce que l'homme est une forme de communication en soi.

Cette situation conduit bien sûr à la nécessité de connaître une langue étrangère par sa culture. « Dans le domaine de la didactique des langues étrangères, des notions telles que celles des représentations et d'identité culturelle deviennent primordiales car elles problématisent la relation que l'apprenant entretient d'une part avec la culture étrangère enseignée et d'autre part avec sa propre identité » (Boubakour, 2010). Du fait que l'apprentissage d'une langue étrangère rend nécessaire la connaissance de la culture de la langue maternelle des apprenants et celle de la langue cible, le développement de l'interculturalité est important chez les apprenants.

Le cadre européen commun de référence pour les langues qui est le guide le plus important pour l'enseignement/apprentissage de langue étrangère et qui forme la base de l'approche actionnelle, inclut l'acquisition du multilinguisme et des compétences multiculturelles dans la mesure possible.

\section{Méthode}

\section{La Méthode de la Recherche}

Notre étude, est une recherche descriptive basée sur le modèle d'analyse documentaire. Nous avons abordé un manuel pour le niveau A1, Saison 1. C'est une méthode de français pour les grands adolescents ou adultes qui apprennent le français comme langue étrangère. Nous avons recherché les éléments culturels et interculturels en termes d'images, de textes et vocabulaires.

\section{Le Choix du Matériel Présenté}

En tant que matériel, nous avons analysé Saison 1, un manuel de FLE pour les grands-adolescents ou adultes. C'est une méthode de français qui a été publiée par Didier, une maison d'édition connue en didactique du FLE, en 2015. Ce manuel a été formé selon les critères de l'approche actionnelle. Le niveau du manuel est A1, mais les deux dernières unités sont distinguées au niveau A2. Saison 1 est un manuel qui est étudié au lycée de Galatasaray.

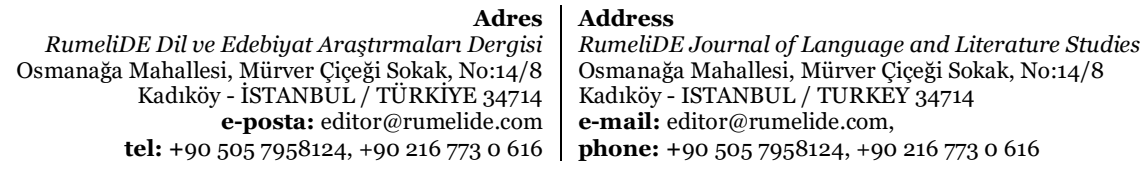




\section{L’Analyse des Données et Exemples}

L'analyse des exemples et des données est principalement basée sur les éléments culturels en termes d'images, de textes et vocabulaires. Nous avons voulu déterminer sur quels thèmes les éléments culturels sont présentés les plus. Et nous avons abordé en particulier les éléments culturels sous la perspective de : la culture française, la culture francophone et le multiculturalisme. Enfin, nous avons analysé les situations d'utilisation des éléments culturels en vue de développer les compétences langagières.

\section{Les Limites de l'Etude}

Nous avons étudié seulement le livre de l'élève, mais pas les cahiers d'activité ni le guide du professeur. Notre analyse contient les visuels, textes et vocabulaires qui ont une dimension culturelle.

\section{Données}

\section{L’information Générale Sur le Manuel et les Thèmes Abordés}

Saison 1 est une méthode de français qui a été publiée par Didier, une maison d'édition connue en didactique du FLE, en 2015. Le public visé de ce manuel est les apprenants grands-adolescents ou adultes. Son niveau est A1, mais les deux dernières unités sont distinguées au niveau A2. Ce manuel s'appuie sur les principes décrits par le CECRL et est formé selon les critères des approches communicative et actionnelle (Heu, Houssa, Kasazian, 2015, 4). Saison 1 contient des audios, vidéos, images et textes. Les documents didactiques et authentiques sont riches et parmi lesquels se trouvent les éléments culturels. Par ces documents on effectue des activités riches à l'oral et à l'écrit.

Le manuel se compose de 3 modules et chaque module de 3 unités. Au début, il se trouve une unité nommée o. Au total, il y a 10 unités. Chaque unité est organisée selon le contenu suivant : le socioculturel, la communication, la grammaire, le lexique et la phonétique. Cette structure indique que le manuel réserve une place importante à la dimension socio-culturelle.

Tableau 1. Les Noms Des Modules/Unités et les Thèmes Socioculturels

\begin{tabular}{lll}
\hline Unité & $\begin{array}{l}\text { Noms des } \\
\text { modules et unités }\end{array}$ & Thèmes Socioculturels \\
\hline o & $\begin{array}{l}\text { Mes cinq sens en } \\
\text { action }\end{array}$ & $\begin{array}{l}\text { 1) les monuments français 2) les salutations françaises 3) à vos souhaits 4) } \\
\text { tu/vous 5) la monnaie la fête nationale }\end{array}$ \\
Mod 1 & $\begin{array}{l}\text { Entrer en contact } \\
1\end{array}$ & $\begin{array}{l}\text { 1) des portraits de personnalités francophones 2) des fiches d'artistes } \\
\text { francophones 3) la politesse 4) poème de Michel Monnereau }\end{array}$ \\
2 & $\begin{array}{l}\text { Partager son lieu de } \\
\text { vie }\end{array}$ & $\begin{array}{l}\text { 1) les français et leur habitat 2) des habitations insolites en France et en Suisse } \\
\text { 3) petite annonce pour un meublé à Paris 4) des nouveaux voisins 5) extrait } \\
\text { littéraire Jus de chaussette, Vincent Remède }\end{array}$ \\
3 & $\begin{array}{l}\text { 1) les loisirs de Français 2) les goûts des autres 3) les activités quotidiennes 4) } \\
\text { l'opéra d Lausanne 5) extrait de la Liste de Rose 6) la routine }\end{array}$ \\
Mod 2 & $\begin{array}{l}\text { Comprendre son } \\
\text { environnement }\end{array}$ & $\begin{array}{l}\text { 1) la vie culturelle en Louisiane 2) les pratiques culturelles des Français 3) } \\
\text { sortir à Montréal 4) le musée Louvre-Lens 5) un billet de théâtre/cinéma }\end{array}$ \\
& $\begin{array}{l}\text { S'ouvrir à la culture } \\
\text { Goûter à la } \\
\text { campagne }\end{array}$ & $\begin{array}{l}\text { 1) un village français 2) le festival du Mot 3) cuisine d'une Parisienne } \\
\text { d'adoption 4) passer à la table 5) payse ses achats }\end{array}$ \\
\hline
\end{tabular}

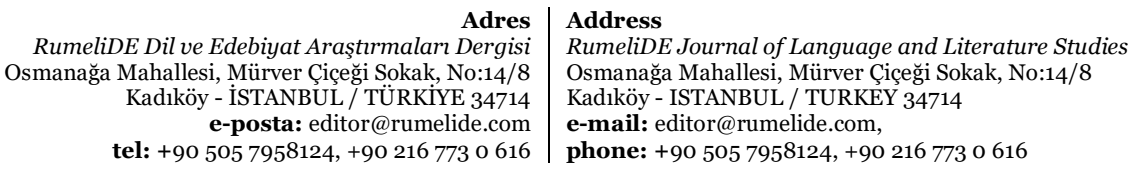




\begin{tabular}{|c|c|c|}
\hline 6 & Voyager dans sa ville & $\begin{array}{l}\text { 1) Bruxelles 2) les applis pour visiter Bruxelles 3) Visite guidé du Vieux-Lyon } \\
\text { 4) la chasse au trésor sur Smartphone 5) une visite à Angers 6) le quartier } \\
\text { Saint Augustin à Bordeaux }\end{array}$ \\
\hline Mod 3 & Changer de vie & \multirow{2}{*}{$\begin{array}{l}\text { 1) garnd-père, père, petit-fils, un passé partagé 2) la brocante de Courpière, 3) } \\
\text { Décoration décup' 4) leboncoin fr 5) le gaspillage et la récupération en France } \\
\text { et en Suisse }\end{array}$} \\
\hline 7 & $\begin{array}{l}\text { Faire du neuf avec } \\
\text { du vieux }\end{array}$ & \\
\hline 8 & Changer d'agir & $\begin{array}{l}\text { 1) les études à l'étranger, Erasmus 2) l'expatriation 3) les formalités } \\
\text { administratives 4) la santé 5) Nicolas Buvier, L'oil du voyageur 6) Bourse } \\
\text { projet }\end{array}$ \\
\hline 9 & Devenir éco-citoyen & $\begin{array}{l}\text { 1) la citoyenneté au quotidien 2) le droit de vote en France et en Belgique 3) } \\
\text { l'écovolontariat 4) les Restos du cœur 5) la vie d'Olympe de Gouges }\end{array}$ \\
\hline
\end{tabular}

Lorsque l'on jette un coup d'œil sur les thèmes abordés dans le cadre socioculturel, ce sont plutôt relatifs à la vie quotidienne. Cependant il existe aussi certains documents culturels comme les textes littéraires, les arts et les monuments. Et on peut dire que l'on donne place à tout afin de continuer une communication efficace en langue cible avec les autres.

\section{La Part d'Images, de Textes et Vocabulaires Culturels}

Les images : Les études sur la conception visuelle et l'apprentissage visuel sont menées dans de nombreux domaines. Lorsqu'on considère ce cas du point de vue de processus d'éducation et de formation, on constate une approche efficace dans tous les domaines de la science. Cette approche est définie comme alphabétisation visuelle. Pour cette raison, depuis longtemps les chercheurs, les pédagogues et les linguistes continuent leurs recherches au sujet de l'utilisation des matériels visuels pour but de l'enseignement/apprentissage des langues étrangères. Les images attirent l'attention des apprenants, leur utilisation augmente la motivation et facilite l'apprentissage.

A peu près à propos de tous les thèmes abordés dans les unités il est possible de trouver des visuels culturels. Non seulement les images de la culture historique, mais aussi celles de la culture vivante prennent place sur les pages. Quant aux genres de document exploités, ce sont: les images des monuments, les photos des gens célèbres, les biographies, les articles, les recettes, les écrits de voyages, etc. Pourtant, on peut dire que c'est l'extrait de magazine qui vient en premier. Par exemple les modes de vie sont conçues comme une part de culture. De l'Arc du Triomphe à la baguette ou du sport à la cuisine il existe des images sur la culture française. Sur les pays francophones comme Canada, Belgique et Suisse plusieurs images sont mentionnées. Cependant il n'y a que 3 images culturels sur les autres pays dans ce manuel. Ce n'est pas une bonne approche au nom de l'interculturalité.

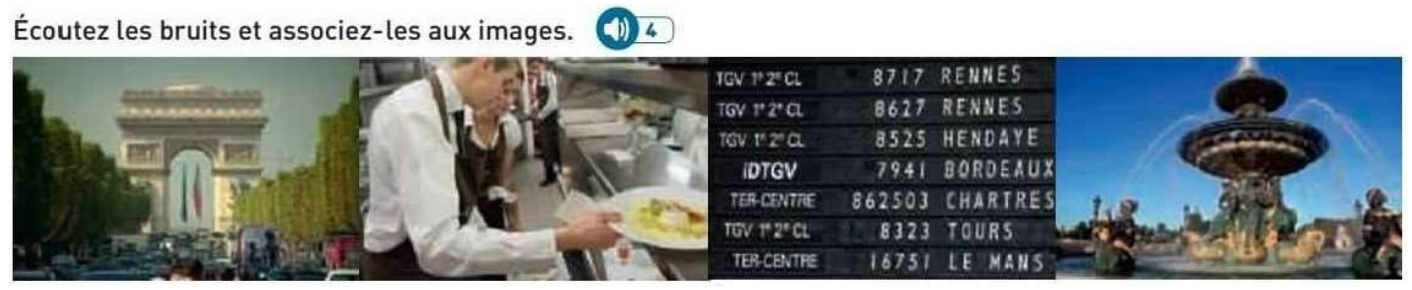

Figure 1. Une avenue à Paris, une cuisine et une fontaine (Heu, Houssa, Kasazian, 2015, 16).

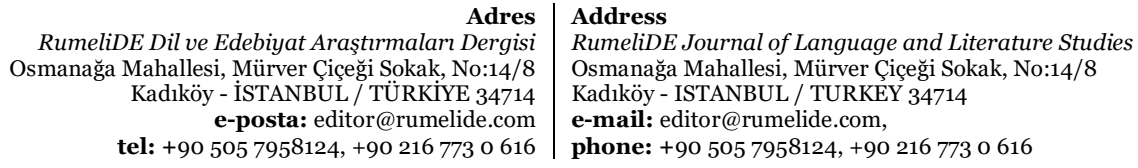

RumeliDE Dil ve Edebiyat Araştırmaları Dergis tel: +90 $5057958124,+902167730616$ 
Dans la rue

A la gare
Dans la cuisine d'un restaurant

Près d'une fontaine

Sur cette page il existe trois images culturelles : l'Arc du Triomphe, une cuisine, une fontaine.

Dans l'unité 3, il se trouve des images de fêtes. La première image est fête des Lumières à Lyon. La deuxième est fête médiévale, la troisième est fête du citron à Menton. Par ici, les apprenants peuvent connaître des fêtes religieuses et nationales, et aussi les activités sur la culture de fêter en France.

Dans l'unité 4, le manuel utilise des images de Montréal comme la patinoire, le parc d'attraction, le musée, Pointe -à -Caillère et le Biodôme. Par ces images, les apprenants peuvent connaitre ces lieux ou monuments et savoir des informations sur des activités qu'on peut faire à Montréal.

Dans l'unité 5, pour la culture cuisinière, le manuel donne place aux exemples de la Suisse qui est un autre pays francophone. Ainsi, les apprenants peuvent connaitre non seulement la gastronomie française, mais aussi celle de la Suisse. On présente le célèbre fromage d'alpage de montagne.

Dans l'unité 6, le manuel présente la capitale de Belgique. Pour faire connaître Bruxelles on choisit certaines places de Bruxelles. Grâce à ces images, les apprenants découvrent la vision d'une autre culture francophone. Par ces images les apprenants acquissent certaines remarques sur Bruxelles, qu'est-ce qu'on mange et qu'est-ce qu'on fait?

Les textes : Dans ce manuel il y a plusieurs textes ou plutôt notes qui peuvent être acceptés comme documents culturels. Les textes littéraires et les affiches de films sont des textes importants concernant des dimensions culturelles.

Dans l'unité 1, par exemple, on présente la culture d'employer les numéros de téléphone en France. Ainsi, les apprenants peuvent apprendre comment ils peuvent dire leurs numéros de téléphone à quelqu'un ou quand quelqu'un dit son numéro de téléphone comment ils doivent le comprendre. L'unité 3 contient un article sur les loisirs préférés des français. Avec cet article le livre explique qu'est-ce que les français aiment faire comme loisirs. Dans l'unité 4, il y a un texte qui présente la vie culturelle en Louisiane. Le manuel partage quelques festivals. Ainsi les apprenants apprennent les noms de festival, le lieu de festival, des expositions en Louisiane. On observe une carte d'un festival dans laquelle il y a des programmes de fête : qu'est-ce qu'on peut faire, quelles sont des activités dès l'ouverture du festival. L'unité 6 présente un blog qui fait connaître une ville. Cette ville est Bordeaux qui se trouve dans la côte Sud-ouest de la France. On partage des pensées d'une personne sur la ville. Dans l'unité 9, il y a un document pour expliquer et informer les droits du citoyen, le système de vote en France et en Belgique. On donne la parole aux gens. Ils expliquent leurs expériences. Ainsi, les apprenants peuvent avoir de connaissance sur le système de vote et les droits du citoyen qui sont en pratique.

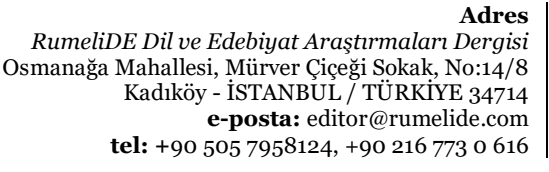

Adres RumeliDE Dil ve Edebiyat Araşttrmaları Dergisi
Osmanağa Mahallesi, Mürver Çiçeği Sokak, No:14/8 e-posta: editor@rumelide.com tel: +90 $5057958124,+902167730616$
Address

RumeliDE Journal of Language and Literature Studies

Osmanağa Mahallesi, Mürver Çiçeği Sokak, No:14/8

Kadıköy - ISTANBUL / TURKEY 34714

e-mail: editor@rumelide.com,

phone: +90 5057958124 , +90 2167730616 


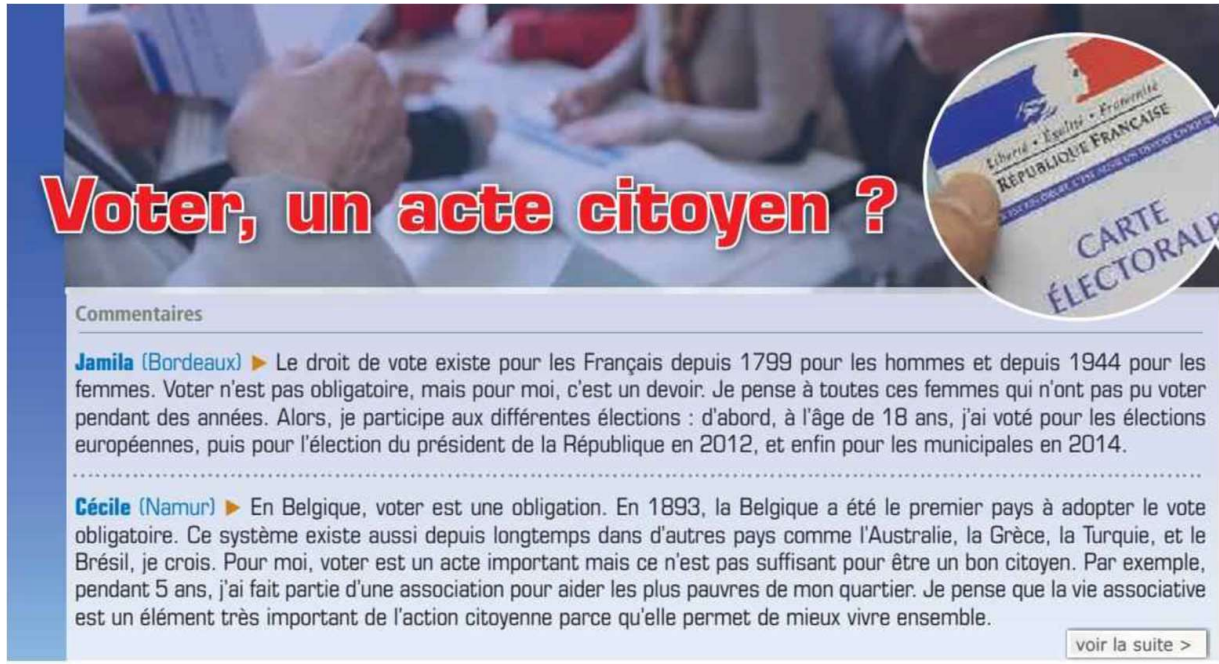

5 Observez la photo en haut à droite.

Mots et expressions

a. Que voyez-vous?

b. À votre avis, quand est-ce qu' on utilise ce document?

c. Quelle est la devise de la République française?

\section{Lisez le document.}

a. Quel est le thème du tchat?

b. Jamila et Cécile sont de quelle nationalité ?

c. Le vote est-il obligatoire dans leur pays ?

d. Voter est-il un acte aussi important pour Jamila et Cécile ?

Pourquoi?

Vie politique et citoyenneté

- le président de la Républiqu

- les élections /municipales/

européennes)

- le vote

- Liberté, Égalité, Fraternité

……….........

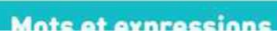

Figure 2. Un texte sur les droits du citoyen (Heu, Houssa, Kasazian, 2015, 173).

Les vocabulaires :

Surtout dans les unités o, 1, 2 et 3 plusieurs vocabulaires ayant un rapport avec la dimension culturelle sont présents. S'il faut citer quelques exemples de la culture française ; la Tour Eiffel, le musée du Louvre, le château du Chambord, le mont-saint Michel, la baguette, les macarons, le marseillaise, le breton, Marche de noël, Le carnaval de Dunkerque, La fête du citron, Médiévales de Provins, Fête de la musique, Fête nationale du 14 Juillet, Fête de la gastronomie. Quant aux exemples de la culture francophone; on voit des mots et des noms comme La Saint Jean Baptiste, Tarte au sirop d'érable et quelques dates qui figurent la culture québécoise, Belfort, Musée des Beaux-Arts, Musée d'art sur Mer, Mini-Europe, Groeningemuseum, Musée Magritte qui représentent la culture Belgique. Il ne s'agit pas d'exemples du multiculturalisme.

RumeliDE Dil ve Edebiyat Arasturmalar Adres Osmanağa Mahallesi, Mürver Ciçeği Sokak No:14/8 Kadıköy - ISTANBUL / TÜRKIYE 34714 e-posta: editor@rumelide.com tel: +90 $5057958124,+902167730616$
Address

RumeliDE Journal of Language and Literature Studies Osmanağa Mahallesi, Mürver Çiçeği Sokak, No:14/8

Kadıköy - ISTANBUL / TURKEY 34714

e-mail: editor@rumelide.com,

phone: +90 5057958124, +90 2167730616 


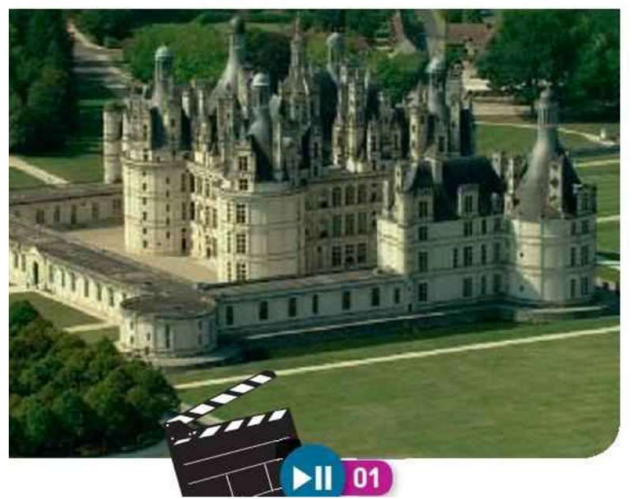

\section{Rendez-vous en France}

a. Regardez la vidéo et retrouvez ces monuments.

Puis replacez-les sur la carte dans votre livre.

- La tour Eiffel

- Le musée du Louvre

- Le château de Chambord

- Le Mont Saint-Michel

b. Associez ces mots à une image vidéo.

la baguette - les macarons - le marché - la musique - le ski -

le bateau-mouche

c. Et vous, quelles images avez-vous de la France?

Figure 3. Quelques noms de monuments à Paris (Heu, Houssa, Kasazian, 2015, 14).

Dans l'unité o il y a quatre «points de culture ». Dans chacune des autres unités il se trouve une partie nommée " actu culture». Dans ces parties la focalisation sur la dimension culturelle est dominante. Pourtant il faut déterminer que les autres parties de manuel couvrent également les éléments culturels. Ici, nous abordons la fréquence d'utilisation des éléments culturels dans les unités et nous faisons des classifications selon les leur type : image, texte, vocabulaire.

Dans le tableau suivant les abréviations représentent: $\mathrm{u}$ :unité, i :image, $\mathrm{t}$ :texte, $\mathrm{v}$ :vocabulaire, ap :autres parties, ac :actu culture.

Tableau 2. Les Nombres des Images, Textes et Vocabulaires Concernant des Éléments Culturels

\begin{tabular}{|c|c|c|c|c|c|c|c|c|c|c|c|c|c|c|c|c|c|c|c|c|}
\hline $\begin{array}{ll}\mathrm{u} & \mathrm{o}\end{array}$ & & 1 & & 2 & & 3 & & 4 & & 5 & & 6 & & 7 & & 8 & & 9 & & \\
\hline ap & ac & ap & $\mathrm{ac}$ & ap & $\mathrm{ac}$ & ap & $\mathrm{ac}$ & ap & $\mathrm{ac}$ & ap & ac & ap & ac & ap & ac & ap & ac & ap & ac & \\
\hline 8 & - & 26 & 7 & 14 & 6 & 4 & 3 & 17 & 9 & 9 & 3 & 12 & 7 & 1 & 7 & 1 & 4 & 2 & 7 & 147 \\
\hline- & 4 & 1 & 6 & 8 & 6 & 5 & 3 & 6 & 10 & 6 & 7 & 7 & 4 & 3 & 7 & 1 & 6 & 4 & 6 & 100 \\
\hline 24 & - & 32 & 16 & 9 & 13 & 7 & 16 & 7 & - & 3 & 5 & 7 & 3 & 1 & 1 & - & 7 & 2 & 7 & 160 \\
\hline 32 & & 59 & & 31 & & 16 & & 30 & & 18 & & 26 & & 5 & & 2 & & 8 & & 227 \\
\hline 4 & & 29 & & 25 & & 22 & & 19 & & 15 & & 14 & & 15 & & 17 & & 20 & & 180 \\
\hline 36 & & 88 & & 56 & & 38 & & 49 & & 33 & & 40 & & 20 & & 19 & & 28 & & \\
\hline
\end{tabular}

Chaque unité couvre des images, des textes et des vocabulaires ayant des dimensions culturelles. Du fait que la priorité de ce manuel est de présenter la culture de la vie quotidienne de la société où la langue cible est parlée, il est possible de prendre en considération plusieurs éléments comme des éléments culturels. Et surtout aborder les vocabulaires dans cette perspective a augmenté le nombre des éléments conçus culturels. Au total il existe 407 éléments culturels. Les vocabulaires sont au sommet par le chiffre 160 et son pourcentage est 39,3\%. Les images les suivent par le chiffre 147 et son pourcentage est 36,1 \%. Quant aux textes, ils sont au dernier rang par le chiffre 100 et son pourcentage est $24,5 \% .180$ éléments culturels (45,3\%) se trouvent dans les parties « actu culture » et 227 (55,7\%) éléments culturels dans les autres parties du manuel.

Les plus nombreux éléments culturels sont présents dans l'unité 1 par le chiffre 88. L'unité 8 concerne les moins nombreux éléments culturels par le chiffre 19. L'unité 1 est au sommet par 29 éléments culturels dans la partie " actu culture » et 59 éléments culturels dans les autres parties. Le nom du module 1 sous lequel prend place l'unité 1 est « entrer en contact », le nom de l'unité 1 « s'ouvrir aux

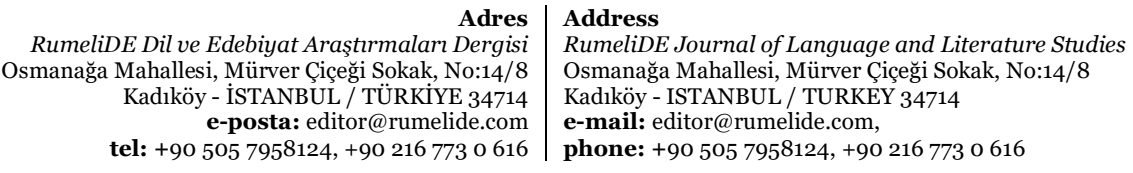


autres » et les thèmes socioculturels «1) des portraits de personnalités francophones 2) des fiches d'artistes francophones 3) la politesse 4) le poème de Michel Monnereau »

Dans l'unité o, il existe 4 points culturels. Dans le premier on fait connaître les salutations françaises sois verbal, soit non verbal. Dans le deuxième on explique l'emploi de tu et vous dans la communication et quand on dit «à tes souhaits et à vos souhaits ». Dans le troisième on parle de l'euro et de son utilisation et dans le cadre de multiculturalisme on demande aux apprenants de parler de la monnaie de leur pays. Dans le quatrième on fait connaître la fête nationale, 14 Juillet et on demande aux apprenants de parler de la fête nationale de leur pays.

Dans les parties « actu culture » on présente généralement des savoirs et il y a un exercice de quiz vrai ou faux sur le thème abordé. En tant que compétence, il s'agit plutôt du développement de la production orale et parfois du développement de la compréhension de l'écrit. Dans le cadre sociolinguistique et dans le contexte socio-culturel l'actu culture de l'unité 1 contient l'emploi de l'expression idiomatique « ça n'est pas ma tasse de thé (je n'aime pas jouer aux jeux vidéo) » et on demande aux apprenants s'il se trouve une expression idiomatique similaire dans leur culture. L'actu culture de l'unité 2 concerne l'emploi de l'expression idiomatique « ce n'est pas la mère à boire (ce n'est pas impossible à faire) ». L'actu culture de l'unité 3 donne place à une expression idiomatique québécoise "être aux petits oiseaux (être très heureux) ", on cite son équivalent en France " être aux anges ». L'actu culture de l'unité 4 couvre l'emploi de l'expression idiomatique « ne pas avoir sa langue dans sa poche (ne pas avoir peur de parler aux gens) ». Dans l'unité 4, il s'agit de l'utilisation d'un texte pour développer la compréhension de l'écrit. Dans l'unité 5 , l'actu culture possède 7 textes pour développer la compétence de la compréhension de l'écrit et la compétence de la production orale. Et dans le cadre de multiculturalisme on demande aux apprenants de citer un cuisinier célèbre de leur pays. L'expression idiomatique de cette unité est "manger sur le pouce (manger très rapidement) ». Dans l'unité 6, un texte est au service de la prononciation, il se trouve des questions sur la Belgique et on demande aux apprenants de comparer la France et la Belgique, ces activités sont pour développer la production orale. L'actu culture de l'unité 6 donne place à une expression idiomatique belge « il drache (il pleut beaucoup) ». L'actu culture de l'unité 7 couvre l'emploi de l'expression idiomatique « c'est la goutte d'eau qui fait déborder le vase (une action en trop qui déclenche la colère de quelqu'un) ». Dans cette partie il y a des questions par lesquelles on demande aux apprenants de développer leur compétence de production orale. Dans l'unité 8 il existe des questions pour développer la compréhension de l'écrit. L'actu culture del'unité 8 contient l'emploi de l'expression idiomatique « avoir le cœur sur la main (être très généreux). Dans cette unité on fait connaître le nomade français célèbre ». L'unité 9, dans le cadre de multiculturalisme, prend en considération la culture de la langue source et on pose une question, c'est pour développer la production orale. L'expression idiomatique est « avoir du cœur au ventre (faire preuve de courage).

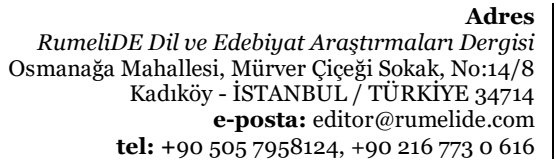

Adres

RumeliDE Dil ve Edebiyat Araştırmaları Dergisi Kadıköy - ISTANBUL / TÜRKIYE 34714 tel: +90 $5057958124,+902167730616$
Address

RumeliDE Journal of Language and Literature Studies

Osmanağa Mahallesi, Mürver Çiçeği Sokak, No:14/8

Kadıköy - ISTANBUL / TURKEY 34714

-mail: editor@rumelide.com,

phone: +90 5057958124 , +90 2167730616 


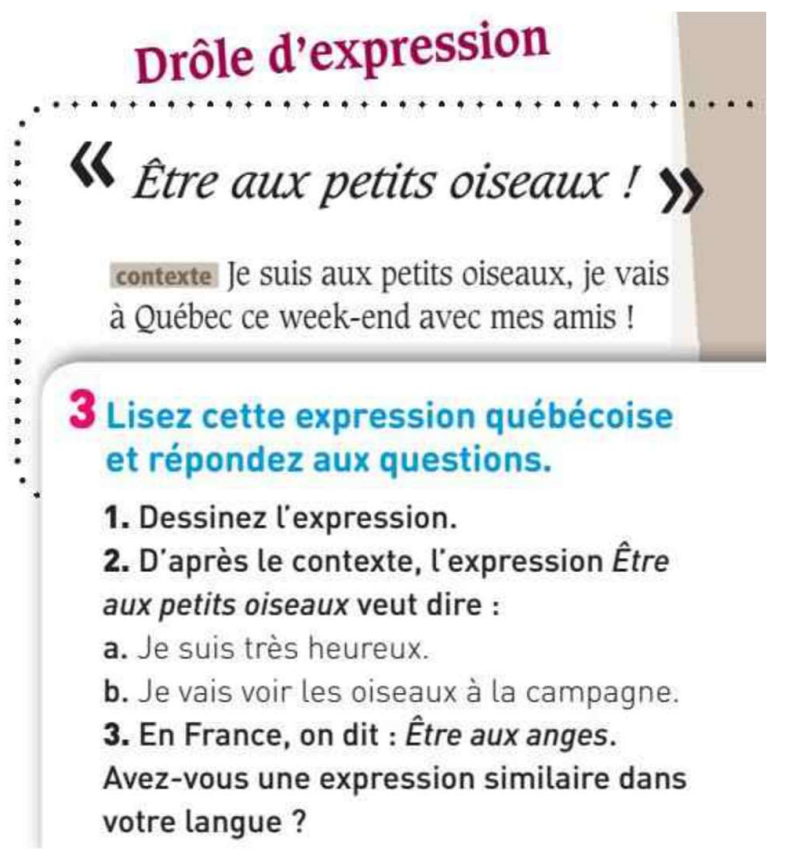

Figure 4. Une expression idiomatique (Heu, Houssa, Kasazian, 2015, 73).

Pour la dimension culturelle, la plus importante différence de ce manuel, c'est que dans le cadre de sociolinguistique il donne place à une expression idiomatique de la culture française ou de la culture francophone dans chaque partie « actu culture » parce que « la compétence sociolinguistique renvoie aux paramètres socioculturels de l'utilisation de la langue. Sensible aux normes sociales (règles d'adresse et de politesse, régulation des rapports entre générations, sexes, statuts, groupes sociaux, codification par le langage de nombre de rituels fondamentaux dans le fonctionnement d'une communauté), la composante sociolinguistique affecte fortement toute communication langagière entre représentants de cultures différentes, même si c'est souvent à l'insu des participants eux-mêmes. » (CECRL, 2001, 18). Ainsi, les apprenants apprennent l'utilisation de certaines expressions idiomatiques dans un contexte socio-culturel.

\section{La Culture Française, la Culture Francophone et le Multiculturalisme}

Dans cette partie nous abordons les éléments culturels dans le cadre de culture française (les exemples de la France), de culture francophone (les exemples des pays francophones) et de multiculturalisme (les exemples d'autres pays).

Tableau 3. Les Eléments sur la Culture Française, la Culture Francophone et le Multiculturalisme

\begin{tabular}{|c|c|c|c|c|c|c|c|}
\hline \multirow[t]{2}{*}{ Unité } & \multirow[t]{2}{*}{ Types de document } & \multicolumn{2}{|c|}{ Culture française } & \multicolumn{2}{|c|}{ Culture francophone } & \multicolumn{2}{|c|}{ Multiculturalisme } \\
\hline & & a. parties & a. culture & a. parties & a. culture & a. parties & a. culture \\
\hline \multirow[t]{3}{*}{$\mathbf{o}$} & images & 7 & - & 4 & - & 1 & - \\
\hline & textes & - & 4 & - & - & - & - \\
\hline & vocabulaires & 11 & - & 4 & - & 9 & - \\
\hline \multirow[t]{3}{*}{$\mathbf{1}$} & images & 3 & 7 & 14 & - & 9 & - \\
\hline & textes & - & 6 & 1 & - & - & - \\
\hline & $\begin{array}{r}\text { RumeliDE Dil ve Ede } \\
\text { Osmanağa Mahallesi, } \\
\text { Kadıköy - İs } \\
\text { e-p } \\
\text { tel: }+90505\end{array}$ & $\begin{array}{l}\text { iyat Araştrme } \\
\text { Irver Ciçeği Sol } \\
\text { rANBUL / TÜP } \\
\text { sta: editor@ru } \\
958124,+902\end{array}$ & $\begin{array}{r}\text { Adres } \\
\text { lart Dergisi } \\
\text { ak, No:14/8 } \\
\text { KIYE } 34714 \\
\text { melide.com } \\
67730616\end{array}$ & \multicolumn{4}{|c|}{$\begin{array}{l}\text { Address } \\
\text { RumeliDE Journal of Language and Literature Studies } \\
\text { Osmanăga Mahallesi, Mürver Ciceği Sokak, No:14/8 } \\
\text { Kadlköy - ISTANBUL / TURKEY } 34714 \\
\text { e-mail: editor@ @rumelide.com, } \\
\text { phone: +90 505 7958124, +90 } 216773 \text { o } 616\end{array}$} \\
\hline
\end{tabular}




\begin{tabular}{|c|c|c|c|c|c|c|c|}
\hline & vocabulaires & 5 & 16 & 7 & - & 20 & - \\
\hline \multirow[t]{3}{*}{2} & images & 12 & 6 & 2 & - & - & - \\
\hline & textes & 5 & 6 & 3 & - & - & - \\
\hline & vocabulaires & 8 & 13 & 1 & - & - & - \\
\hline \multirow[t]{3}{*}{3} & images & 1 & 3 & 3 & - & - & - \\
\hline & textes & 2 & 3 & 3 & - & - & - \\
\hline & vocabulaires & 1 & 16 & 6 & - & - & - \\
\hline \multirow[t]{3}{*}{4} & images & 4 & & 9 & 9 & 4 & - \\
\hline & textes & - & - & 5 & 10 & 1 & - \\
\hline & vocabulaires & - & - & 1 & - & 6 & - \\
\hline \multirow[t]{3}{*}{5} & images & 8 & 2 & - & 1 & 1 & - \\
\hline & textes & 5 & 6 & - & 1 & 1 & - \\
\hline & vocabulaires & 3 & 5 & - & - & - & - \\
\hline \multirow[t]{3}{*}{6} & images & 5 & - & 7 & 7 & - & - \\
\hline & textes & 3 & - & 4 & 4 & - & - \\
\hline & vocabulaires & 2 & - & 3 & 3 & 2 & - \\
\hline \multirow[t]{3}{*}{7} & images & 1 & 5 & - & - & - & 2 \\
\hline & textes & 2 & 5 & 1 & - & - & 2 \\
\hline & vocabulaires & 1 & - & - & 1 & - & - \\
\hline \multirow[t]{3}{*}{8} & images & 1 & 3 & - & 1 & - & - \\
\hline & textes & 1 & 4 & - & 2 & - & - \\
\hline & vocabulaires & - & 5 & - & 2 & - & - \\
\hline \multirow[t]{4}{*}{9} & images & 2 & 3 & - & 3 & - & 1 \\
\hline & textes & 2 & 3 & 1 & 3 & 1 & - \\
\hline & vocabulaires & 2 & 7 & - & - & - & - \\
\hline & & 97 & 128 & 79 & 47 & 55 & 5 \\
\hline
\end{tabular}

Lorsque l'on analyse les éléments culturels en termes de culture française, de culture francophone et multiculturalisme, il existe 225 éléments sur la culture française, sa part est 54,7\%. Par le chiffre 126, le pourcentage des éléments sur la culture francophone est 30,6\%. Quant aux éléments concernant une dimension multiculturelle, le nombre est 60 et leur part est $14,5 \%$. Sur la culture française il se trouve 128 (56,8 \%) éléments culturels dans les parties « actu culture » et il y a $97(43,1 \%)$ éléments culturels dans les autres parties du manuel. C'est surtout dans les parties « actu culture » que l'on présente les éléments sur la culture de la langue cible. Sur la culture francophone 47 (37,3\%) éléments sont présentés dans les parties «actu culture» et 79 (62,6 \%) éléments culturels dans les autres parties. Sur le multiculturalisme il existe $5(8,3 \%)$ éléments dans les parties « actu culture » et 55 (91,6\%) éléments culturels dans les autres parties. Ces résultats indiquent que les éléments sur la culture francophone et le multiculturalisme prennent place dans les autres parties du manuel. En outre, alors que les éléments sur la culture française sont dominants par le chiffre128 (56,8 \%) dans les parties " actu culture », les éléments sur le multiculturalisme est très faible par le chiffre $5(8,3)$.

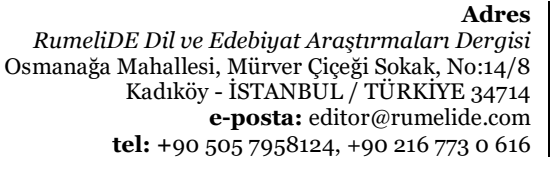

dres

8

Address

RumeliDE Journal of Language and Literature Studies Osmanağa Mahallesi, Mürver Çiçeği Sokak, No:14/8 Kadıköy - ISTANBUL / TURKEY 34714

e-mail: editor@rumelide.com, phone: +90 $5057958124,+902167730616$ 
Le manuel couvre peu d'éléments culturels à propos des autres pays. Cette situation est au détriment du développement des compétences d'interculturalité des apprenants. Sans doute, la priorité doit être donnée à la culture de la société dans laquelle la langue cible est parlée, mais pour effectuer des communications et des interactions efficaces avec les gens des autres pays il est inévitable de connaitre les cultures des autres, y compris la culture de la langue source aussi. Dans ce cas la langue cible doit être conçu plutôt comme un moyen.

\section{Les Objectifs des Exercices et des Activités Pratiqués Dans les Parties de Méthode}

L'utilisation des documents culturels dans les manuels contient des objectifs différents. Ils ne visent pas seulement à citer des savoirs culturels ou à perfectionner des compétences culturelles, mais aussi ils sont utilisés afin de développer les compétences langagières de base et les composantes linguistiques. Ici, nous étudierons les objectifs des exercices, activités et tâches qui sont effectués par les éléments culturels. Dans les parties « actu cultures » les éléments culturels prennent place plutôt pour présenter des savoirs culturels, dans les autres parties du manuel leurs rôles principaux sont de développer les compétences langagières de base et de temps en temps ils sont au service des composantes linguistiques, surtout à celui du vocabulaire.

Tableau 4. Les Objectifs des Exercices, Activités et des Tâches Pratiquées

\begin{tabular}{|c|c|c|c|c|c|c|c|c|}
\hline unité & c. oral & c. écrit & p. orale & p. écrite & vocabulaire & grammaire & phonétique & total \\
\hline $\mathbf{o}$ & 15 & 6 & 3 & - & 14 & 9 & - & \\
\hline $\mathbf{1}$ & 13 & 8 & 14 & 12 & 38 & 3 & - & \\
\hline 2 & 12 & 21 & 12 & 3 & - & 1 & - & \\
\hline 3 & - & 7 & 2 & 1 & - & 1 & - & \\
\hline 4 & - & 17 & 11 & - & 2 & - & - & \\
\hline 5 & 1 & 9 & 8 & - & - & 2 & 2 & \\
\hline 6 & 10 & 12 & 8 & 1 & 7 & - & 2 & \\
\hline 7 & - & 1 & 5 & - & - & - & - & \\
\hline 8 & - & 1 & 2 & - & - & - & - & \\
\hline \multirow[t]{2}{*}{9} & - & 7 & 3 & - & - & - & - & \\
\hline & 51 & 89 & 68 & 17 & 61 & 16 & 4 & 306 \\
\hline
\end{tabular}

De ce tableau on constate que 306 éléments culturels prennent place pour le développement des compétences langagières et des composantes linguistiques. 89 (29\%) éléments culturels sont utilisés en vue de développer la compréhension de l'écrit, 68 (22,2 \%) pour la production orale, 61 (19,9\%) pour le vocabulaire, 51 (16,6\%) pour la compréhension de l'oral, 17 (5,5\%) pour la production écrite, 16 (5,2 \%) pour la grammaire, $4(1,3 \%)$ pour la phonétique. Comme on a indiqué plus avant il n'y a que quelques éléments culturels présentés dans les parties «actu culture » afin de développer les compétences langagières de base, les éléments culturels utilisés aux activités et exercices se trouvent dans les autres parties du manuel. On utilise le plus les éléments culturels pour le développement de la compétence de la compréhension de l'écrit, le moins pour la phonétique.

Pour développer la compréhension de l'écrit et la production orale les éléments culturels sont utilisés dans chaque unité. Pour développer la compréhension de l'oral ils prennent place dans 5 unités et pour développer la production écrite dans 4 unités. S'il faut faire une considération dans le cadre des

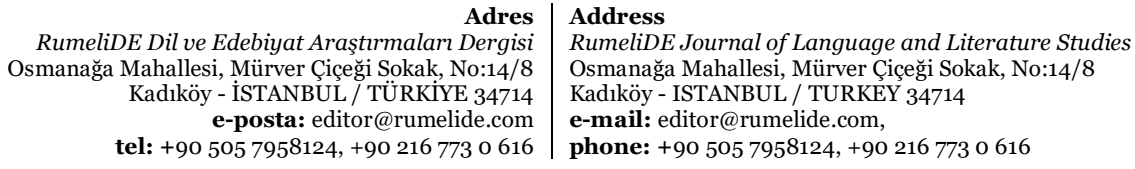


composantes linguistiques bien que les plus nombreux éléments culturels soient présents afin de développer le vocabulaire, dans 4 unités ils sont utilisés pour cet objectif. Pour développer la grammaire ces éléments culturels se trouvent dans 5 unités. Pour améliorer la prononciation ils possèdent un rôle seulement dans 2 unités.

\section{Conclusion et Propositions}

\section{Conclusion}

Les besoins des apprenants ou de la société, les développements technologiques, les travaux sur la linguistique, les recherches dans les sciences de l'éducation jouent un rôle déterminant à la création des méthodes. Les manuels sont formés en prenant en considération ces recherches et ces nouveaux besoins qui peuvent changer du passé au présent. Donc, en tant que ressources fondamentales, les manuels ne sont pas formés seulement pour la connaissance des règles de grammaire ou des structures linguistiques de la langue cible, il est nécessaire qu'ils contiennent des éléments sur la dimension culturelle qui est importante pour l'acquisition de langue étrangère. Puisque la langue et la culture font partie des éléments indissociables, dans ce cas, les éléments culturels sont également importants pour atteindre la réussite. Alors qu'une langue est enseignée à une autre, si on ne fait pas connaître sa culture, qui est l'une des composantes les plus importantes de cette langue, il s'agira d'une absence parce que l'utilisation d'une langue surtout dans la vie quotidienne ne s'appuie pas sur les connaissances théoriques à l'égard de la langue dont il s'agit, mais sur son usage dans la société.

Les thèmes abordés dans le cadre socioculturel sont plutôt relatifs à la vie quotidienne. Cependant il existe aussi certains documents culturels comme les textes littéraires, les arts et les monuments. Chaque unité couvre des images, des textes et des vocabulaires ayant des dimensions culturelles. Au total il existe 407 éléments culturels. Les vocabulaires sont au sommet par le chiffre 160 et son pourcentage est 39,3 $\%$. Les images les suivent par le chiffre 147 et son pourcentage est 36,1\%. Quant aux textes, ils sont au dernier rang par le chiffre 100 et son pourcentage est $24,5 \%$. 180 éléments culturels (45,3\%) se trouvent dans les parties « actu culture » et 227 (55,7\%) éléments culturels dans les autres parties du manuel.

Pour la dimension culturelle, la plus importante différence de ce manuel, c'est que dans le cadre de sociolinguistique il donne place à une expression idiomatique de la culture française ou de la culture francophone dans chaque partie "actu culture». Ainsi les apprenants apprennent l'utilisation de certaines expressions idiomatiques dans un contexte socio-culturel.

Il existe 225 éléments sur la culture française, sa part est 54,7\%. Par le chiffre 126, le pourcentage des éléments sur la culture francophone est 30,6\%. Quant aux éléments concernant une dimension multiculturelle, le nombre est 60 et leur part est 14,5\%. Le manuel couvre peu d'éléments culturels à propos des autres pays. Cette situation est au détriment du développement des compétences d'interculturalité des apprenants. Sans doute, la priorité doit être donnée à la culture de la société dans laquelle la langue cible est parlée, mais pour effectuer des communications et des interactions efficaces avec les gens des autres pays il est inévitable de connaître les cultures des autres aussi.

306 éléments culturels prennent place pour le développement des compétences langagières et des composantes linguistiques. 89 (29\%) éléments culturels sont utilisés en vue de développer la compréhension de l'écrit, 68 (22,2 \%) pour la production orale, 61 (19,9\%) pour le vocabulaire, 51 (16,6 $\%)$ pour la compréhension de l'oral, 17 (5,5\%) pour la production écrite, $16(5,2 \%)$ pour la grammaire,

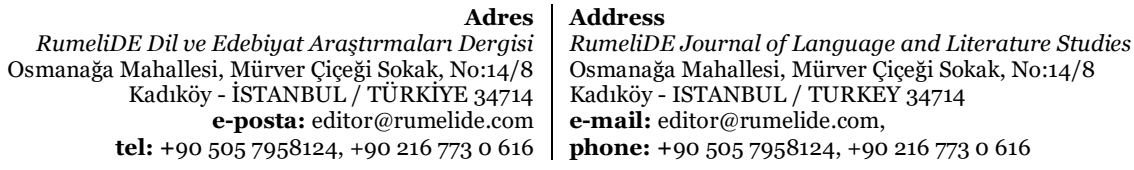


$4(1,3 \%)$ pour la phonétique. On utilise le plus les éléments culturels pour le développement de la compétence de la compréhension de l'écrit, le moins pour la phonétique.

Par conséquent, dans le manuel Saison 1 on utilise les éléments culturels pour développer toutes les compétences langagières de base, les composantes linguistiques, et de plus pour les compétences communicatives et interculturelles.

\section{Propositions}

- Apprendre une langue, ce n'est pas seulement d'avoir des savoirs sur sa grammaire, mais de pouvoir l'utiliser dans le contexte socio-culturel et de pouvoir réaliser une communication efficace dans la langue cible. L'utilisation effective de la langue cible dans la vie quotidienne dépend de connaître sa culture. Pour cette raison, les valeurs et les éléments culturels devraient prendre place dans les manuels.

- De plus, les exercices, les activités et les tâches devraient se focaliser de temps en temps sur la dimension socio-culturelle. Et ces manuels devraient prendre en considération une dimension multiculturelle pour que les apprenants puissent développer leur compétence d’interculturalité.

- Les éléments culturels ne devraient pas prendre place seulement pour citer des savoirs sur la culture, mais ils doivent être utilisés d'une façon active dans les exercices, les activités et les tâches réalisées. Et surtout les exemples de culture vivante devraient être primordiaux en vue de développer efficacement les compétences langagières en langue cible.

\section{Bibliographie}

Aksan, D. (2007). Her Yönüyle Dil, Ana Çizgileriyle Dilbilim, Ankara: Türk Dil Kurumu.

Baylon, C. et Mignot, X. (2005). La Communication. Paris: Armand Colin.

Bertocchini, P. et Costanzo, E. (2008). Manuel de Formation Pratique. Paris: CLE.

Boubakour, S. (2010). L'enseignement des langues-cultures: dimensions et perspectives, Synergies Algérie, 9,13-26.

Byram, M (1992). Language and culture learning for european citizenship. Language and Education 6 (2-4), 165-176.

Byram, M., Zarate, G., \& G. Neuner. (1997), La compétence socioculturelle dans l'apprentissage et l'enseignement des langues Vers un Cadre européen commun de référence pour l'apprentissage et l'enseignement des langues vivantes: études préparatoires : Conseil de l'Europe.

Conseil de l'Europe, (2001). Cadre européen commun de références pour les langues: apprendre, enseigner, évaluer. Paris: Didier.

Cuq, J.P. (2009). Le Cadre européen, une référence mondiale? La FIPF Dialogues et Cultures, 54.

Er, K.O. (2006), The Effects of culture in foreign language Curriculum, Ankara University, Journal of Faculty of Educational Sciences, 39 (1), 1-14.

Günday, R. et Aycan, A. (2018). Yabancı dil öğreniminde kültürlerarası iletişim becerisi edinimi, International Journal of Languages' Education and Teaching, IJLET, 6/3, 533-545.

Heu, E. , Houssa, C. , Kasazian, E. (2015). Saison 1, Paris: Didier

Jiang, W. (2000). The realation between culture and language. ELT Journal Volume, 328-334. Consulté le 09 07, 2005, sur http://eltj.oxfordjournals.org/cgi/reprint/54/4/328.pdf.

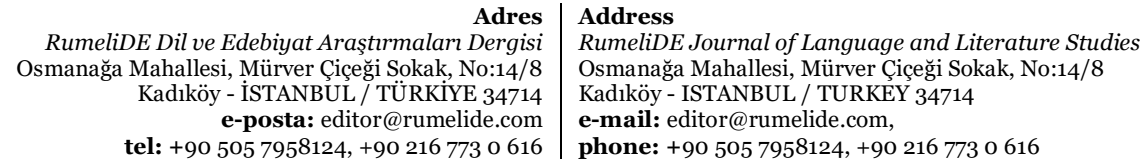


Kartal, E. (2001). Apprentissage / enseignement de la culture / civilisation dans les manuels utilisés en didactique du français langue étrangère, Uludağ Üniversitesi Ĕ̆itim Fakültesi Dergisi, XIV (1),110.

Lázár, I., Huber-Kriegler, M., Lussier, D., Matei, G. S., \& Peck, C. (2007), Développer et évaluer la compétence en communication interculturelle: Un guide à l'usage des enseignants de langues et des formateurs d'enseignants. Strasbourg : Council de l'Europe http://archive.ecml.at/mtp2/ publications/B1_ICCinTE_F_internet.pdf, 21.04.2017.

Nijenkamp, L. (2017). Les éléments culturels et interculturels dans les manuels scolaires D'accord et Grandes Lignes. Mémoire de master, Université d'Utrecht.

Puren, C. (2004). De l'approche par les tâches à la perspective co-actionnelle. Les Cahiers de l'APLIUT, 23 (1), 10-26.

Puren, C. (2002). Perspectives actionnelles et perspectives culturelles en didactique des langues: vers une perspective co-actionnelle-co-culturelle. Les Langues Modernes, 3/2002, 55-71.

Richards, J.C. (2006). Communicative Language Teaching Today, Cambridge University Press,13 2-6.

Riquois, E. (2010). Évolutions méthodologiques des manuels et matériels didactiques complémentaires en FLE, $H A L$, 129-142.

Risager, K. (2007), Language and Culture Pedagogy : From a National to a Transnational Paradigm : From a National to a Transnational Paradigm. Clevedon, GB: Multilingual Matters.

Rosen, E. (2009). Perspective actionnelle et approche par les tâches en classe de langue. Le français dans le Monde, Janvier 2009.

Sow, A. (2009). L’importance des responsabilités et droits culturels dans le développement. Campus Euro-Africano de Cooperaçao Cultural. Mocambique, https://www.interarts.net/ descargas/interarts539. pdf La date de: 06.05.2019.

UNESCO. (1982). Déclaration de Mexico sur les politiques culturelles. Conférence mondiale sur les politiques culturelles, Mexico City, 26 juillet - 6 août 1982.

Yaguello, M. (2003). Le grand Livre de la Langue Française, Paris: Seuil.

RumeliDE Dil ve Edebiyat Araştırmaları Dergisi Osmanağa Mahallesi, Mürver Çiçeği Sokak, No:14/8 Kadıköy - ISTANBUL / TÜRKIYE 34714 e-posta: editor@rumelide.com tel: +90 $5057958124,+902167730616$
Address

RumeliDE Journal of Language and Literature Studies Osmanağa Mahallesi, Mürver Çiçeği Sokak, No:14/8

Kadıköy - ISTANBUL / TURKEY 34714

e-mail: editor@rumelide.com,

phone: +90 5057958124, +90 2167730616 